\title{
Influence of Optimism on Mental Health of College Students
}

\author{
Maryam Jalali Ghalibaf, Ph.D, Dept of Psychology, \\ Osmania University, Hyderabad
}

\begin{abstract}
The present study was taken up to investigate the relationship between optimism and mental health. Samples of 400 college students pursuing their post graduate courses in Hyderabad werepurposively selected for the study. The respondents were administered Revised Life Orientation Test (LOT-R)-by Scheier, Carver \& Bridges, (1994) and mental health inventory. The results of the study revealed that optimism had strong influence on depression dimension of mental health and had no significant influence on total mental health of college students.
\end{abstract}

\section{INTRODUCTION}

Optimism is a tendency to expect good things in the future. From the literature here reviewed, it is apparent that optimism is a mental attitude that heavily influences physical and mental health, as well as coping with everyday social and working life. Through an adaptive management of personal goals and development and by using active coping tactics, optimists are significantly more successful than pessimists in aversive events and when important life-goals are impaired.Optimistic individuals are positive about events in daily life. In the research carried out regarding this perspective, positive correlations have been found between optimism and physical/mental well-being. Optimistic subjects tend to have more frequently protective attitudes, are more resilient to stress and are inclined to use more appropriate coping strategies.Positive and negative expectations regarding the future are important for understanding the vulnerability to mental disorders, in particular mood disorders.Optimism is not the hope for a desirable event but the expectation of its occurrence (Scheier\& Carver, 1985). Lazarus (1995) stated that when individuals are confident that things will work out positively they feel something akin to optimism, not hope.Optimism may significantly influence mental and physical well-being by the promotion of a healthy lifestyle as well as by adaptive behaviours and cognitive responses, associated with greater flexibility, problem-solving capacity and a more efficient elaboration of negative information.

Objective: To study the effect of optimism on mental health of college students.

Hypothesis:There will be positive effect of optimism on mental health of college students.

\section{METHODOLOGY:}

Sample: Sample includes students of both genders pursuing the post graduation courses in Hyderabad either in science or arts stream. Purposive sampling was adopted to select the sample of particular characteristics which enables to answer the research

Sample size: A sample of 400 Post graduate students from Hyderabad were purposively selected for the study.

Operational definitions:

Mental health:

Psychological wellbeing and satisfactory adjustment to society and to the ordinary demands of life

Self efficacy:

Self efficacy is the belief in one's ability to succeed in specific situations or accomplish a task

Tools:

Tool to measure optimism

Revised Life Orientation Test (LOT-R)-by Scheier, Carver \& Bridges, (1994)

A 10-item measure of optimism versus pessimism. Of the 10 items, 3 items measure optimism, 3 items measure pessimism, and 4 items serve as fillers. Respondents rate each item on a 4-point scale: $0=$ strongly disagree, $1=$ disagree, 2 = neutral, 3 = agree, and $4=$ strongly agree. Scheier, Carver and Bridges report an internal reliability coefficient of .78 The LOT-R has good internal consistency (Cronbach's alpha runs in the high .70s to low .80s) and is quite stable over time. Because of the extensive item overlap between the LOT and the LOT-R, correlations between the two scales are very high. 


\section{Mental Health Inventory (Veit and Ware, 1983)}

The Mental Health Inventory (MHI) is a method for evaluating mental health issues such as anxiety, depression, behavioral control, positive effect, and general distress. This instrument helps in the measure of overall emotional functioning.

The Mental Health Inventory includes 38 items in which the respondent uses a 6 -point Likertstyle response and it can generally be done without help. The test takes approximately 5-10 minutes to administer

Analysis:

\begin{tabular}{|l|l|l|l|l|}
\hline Mental health dimension & Mean & SD & $\mathrm{R}$ & significance \\
\hline Optimism & 20.05 & 3.04 & & \\
\hline Anxiety & 37.18 & 7.610795 & .094 & $.061^{\mathrm{NS}}$ \\
\hline Depression & 18.425 & 4.544158 & .216 & $.000^{* *}$ \\
\hline Loss behavior and emotion & 31.13 & 5.824354 & .110 & $.028^{*}$ \\
\hline General positive affect & 34.9125 & 8.527593 & .088 & $.078^{\mathrm{NS}}$ \\
\hline Emotional ties & 10.2925 & 2.724324 & .052 & $.304^{\mathrm{NS}}$ \\
\hline Total mental health & 131.8875 & 19.45944 & .086 & $.084^{\mathrm{NS}}$ \\
\hline
\end{tabular}

Statistical analysis like frequencies and percentages are used for analysis. Anova, $t$ test was used to study the mean differences. Correlation coefficient and multiple regression was used to study relationship between self efficacy and mental health.

\section{RESULTS AND DISCUSSION}

Table 1: Correlation between optimism and mental health dimension of college students

The correlation between optimism and mental health dimension of college students was presented in the table 1. The results of study show that mean score for optimism was 20.05 and $\mathrm{SD}=3.04$. The pearson correlation analysis reveal a non significant relation between optimism and anxiety with as calculated $\mathrm{r}(.094)$ and $\mathrm{p}(.061)$ values greater than 0.05 level of significance. The correlation coefficient for optimism and depression was found to be .216 with $\mathrm{p}=.000$, hence the study concludes a significant relation between optimism and depression. A significant relation was also found between optimism and loss behaviour and emotion was found with

$\mathrm{r}=.110$ and $\mathrm{p}=0.028$ at 0.05 level of significance. Non significant relationship between optimism and general positive affect and emotional ties dimension of mental health was found with $p$ value $(.078 \& .304)>0.05$ level of significance.

From the analysis it could be concluded that there was no significant relationship between optimism and total mental health of college students, as calculated $r=0.086$ and $\mathrm{p}=0.084>0.05$ level of significance. Rezaei, SG., et.al (2015) study found a significant relationships among optimism, pessimism, and mental health $(\mathrm{p}<0.01)$.

Table2: Regression for optimism effect on mental health of college students

\begin{tabular}{|l|l|l|l|l|}
\hline Mental health dimensions & $\begin{array}{l}\text { Regression coefficient } \\
\mathrm{B}\end{array}$ & $\mathrm{t}$ & $\mathrm{P}$ & Significance \\
\hline Anxiety & .094 & 1.879 & $.061^{\mathrm{NS}}$ & Not Significant \\
\hline Depression & .216 & 4.413 & $0.00^{* *}$ & Significant \\
\hline Loss behavior and emotion & .110 & 2.21 & $.028^{*}$ & Significant \\
\hline General positive affect & .88 & 1.76 & $.078^{\mathrm{NS}}$ & Not Significant \\
\hline Emotional ties & .052 & 1.03 & $.304^{\mathrm{NS}}$ & Not Significant \\
\hline Total & .086 & 1.732 & $.084^{\mathrm{NS}}$ & Not Significant \\
\hline
\end{tabular}

Influence of optimism on mental health of college students is presented in table 2 . The regression analysis shows a non significant effect of optimism on anxiety dimension of mental health with $\mathrm{t}=1.87$ and $\mathrm{p}=$ 
.061. The study concludes that optimism significantly effects Depression dimension of mental health with $\mathrm{p}$ $<0.01$ level of significance. Loss behaviour and emotion also found to be influenced by optimism in college students at 0.05 level of significance. Regression for general positive affect interpreted that optimism had a non significant effect as $\beta=.88$ with $t=1.76$ and $p>0.05$ level significance. Optimism had no significant effect on emotional ties dimension as the calculated $\mathrm{p}$ value $>0.05$. The study concludes that optimism had no significant influence on total mental health of college students. JavadKhalatbari (2012) examined the relation between optimism and mental health in students. Results showed that optimism has a positive direct relationship with mental health. Result of this study shows the more pessimistic someone is, the more he has mental health. The study concludes that optimism had significant effect on depression and loss behaviour and emotions dimensions of mental health. Optimism had not shown any significant effect on other mental health dimensions like anxiety, general positive affect, and emotional ties and also on total mental health. Therefore the hypothesis that there will be positive effect of optimism on mental health of college students is rejected.

\section{CONCLUSION}

The study concludes that optimism only effects the depression dimension of mental health. Though it is found to have no significant influence on total mental health, being optimistic alleviates the depression and enhances the quality of life which indirectly improves the mental health.

\section{REFERENCES}

[1] JavadKhalatbari (2012) the relationship between optimism and mental health in a non-profit student branch of tonekabon, Indian Journal of Fundamental and Applied Life Sciences ISSN: 2231-6345 (Online)2012 Vol. 2 (2) April-June, pp.304-31

[2] Lazarus, R. S. (1995). Psychological stress in the workplace. In R. Crandall, \& P. L. Perrewé (Orgs.), Occupational stress: A Handbook (pp. 3-14). Washington: Taylor \& Francis.

[3] Rezaei, S. ,Mousavi, S. , Safari, F. , Bahrami, H. and Menshadi, S. (2015) Study of Relationship between Optimism, Pessimism and Coping Strategies with Mental Health among University Students of Lorestan. Open Journal of Social Sciences, 3, 190-195. doi: 10.4236/jss.2015.312021.

[4] Scheier, M.F. and Carver, C.S. (1985) Optimism, Coping and Health: Assessment and Implication of Generalized Outcome Expectancies. Health Psychology, 4, 219-247. 